khớp gối không cao. Nghiên cứu chúng tôi có khác biệt khá lớn so với các tác giả hiện nay vì cõ mẫu không lớn, tiêu chuẩn nhận bệnh khắt khe hơn.

3.3. Đánh giá các biến chứng: Chúng tôi ghi nhận có 1 trường hợp biến chứng (16.7\%): 1 trường hợp can xấu, hẹp khe khớp nhiều và cứng khớp gối, không ca nào nhiễm trùng hoặc có biến chứng về thần kinh, mạch máu, không ca nào bắn vít vào khớp.

\section{KẾT LUÂ̂N}

Gãy kín mâm chày loại $\mathrm{V}$ - VI theo Schatzker gặp nhiều ở nam giới, trong độ tuổi lao động thường gặp tai nạn giao thông cũng như cồng việc đi lại nhiều hay ở trên cao. Việc sử dụng hai nẹp vít khóa kết hợp xương gãy kín mâm chày loại V - VI theo Schatzkermang lại kết quả phục hồi giải phẫu tốt và rất tốt. Chức năng khớp gối ổn định hơn với $66.7 \%$ phục hồi đạt tốt và rất tốt.

\section{TÀI LIÊU THAM KHẢO}

1. Hoàng Khắc Xuân (2020), "Điều trị gãy kín mâm chày Schatzker V, VI bằng nẹp khoá mâm chày ngoài và sau trong qua hai đường mổ" Luận văn bác sĩ chuyên khoa II. Trường đại học Y khoa Pham Ngoc Thach.

2. Đăng Trung Kiên (2015), "Đánh giá kết quả điều trị gã̃y kín mâm chày theo phân loại Schatzker VVi bằng nẹp khoá tại Bệnh viện Việt Đức", Luận văn bác sĩ nội trú, Đại hoc Y Hà Nội.

3. Honkonen S.E., Jarvinen M.J. (1992), "Classification of fractures of the tibial condyles".j Bone Joints Surg Br, 74B(6), 840-847.

4. Insall J.N., Dorr L.D., Scott W.N. (1989), "Rationale of The Knee Society climcal rating system". Clin Orthop, 248, 13-14.

5. Schatzker J. (1992). "Tibia plateau fractures". Skeletal Trauma. Vol.2, pp 1745-1770.

\title{
ĐốI CHIẾU HÌNH ẢNH SIÊU ÂM TỬ CUNG VớI KẾT QUẢ Mô BỆNH HỌC Ở BỆNH NHÂN ĐẾN KHÁM TẠI BỆNH VIỆN ĐẠI HỌC Y THÁI BİNH
}

\author{
Nguyễn Ngọc Trung*, Nguyễn Trung Kiên*, Phí Trọng Hiếu*
}

\section{TÓM TẮT}

Mục tiêu: Đối chiếu hình ảnh siêu âm buồng tử cung với kết quả mô bệnh học. Đối tượng và phương pháp nghiên cứu: Nghiên cứu mổ tả cắt ngang, trên 73 bệnh nhân. Kết quả: Chẩn đoán quá sản niêm mạc tử cung độ nhạy của siêu âm là $13 \%$; độ đặc hiệu là $100 \%$; giá trị chẩn đoán dương tính là $100 \%$ và giá trị chẩn đoán âm tính là $70 \%$. Chẩn đoán polype buồng tử cung độ nhạy trên siêu âm là $81 \%$; độ đặc hiệu là $70 \%$; giá trị chẩn đoán dương tính là $43 \%$ và giá trị chẩn đoán âm tính là $93 \%$. Chẩn đoán u xơ tử cung độ nhạy của siêu âm là $67 \%$; đô đặc hiệu là 94\%; giá trị chẩn đoán dương tính là $60 \%$ và giá trị chẩn đoán âm tính là $95 \%$.

Tư khoá: Buồng tử cung, mô bệnh học, siêu âm

\section{SUMMARY}

CONTRAST IMAGES OF UTERINE

ULTRASOUND WITH HISTOPATHOLOGICAL RESULTS OF PATIENTS EXAMINED AT THAI

BINH MEDICAL UNIVERSITY HOSPITAL

Objectives: To compare ultrasound images of the uterus with histopathological results. Subjects and research methods: A cross-sectional descriptive study, on 73 patients. Results: Diagnosis of

*Đại học Y Dược Thái Binh

Chịu trách nhiệm chính: Nguyễn Ngọc Trung

Email: trungnn@tbump.edu.vn

Ngày nhận bài: 2.01.2021

Ngày phản biện khoa học: 1.3.2021

Ngày duyệt bài: 10.3.2021 endometrial hyperplasia the sensitivity of ultrasound is $13 \%$; specificity is $100 \%$; The positive diagnostic value is $100 \%$ and the negative diagnostic value is $70 \%$. Diagnosis of uterine polype sensitivity on ultrasound is $81 \%$; specificity is $70 \%$; The positive diagnostic value is $43 \%$ and the negative diagnostic value is $93 \%$. Diagnosis of uterine fibroids the sensitivity of ultrasound is $67 \%$; specificity is $94 \%$; The positive diagnosis value is $60 \%$ and the negative diagnostic value is $95 \%$.

Keywords: Uterine chamber, histopathology, ultrasound

\section{I. ĐẶT VẤN ĐỀ}

Các bất thường buồng tử cung như: $u$ xơ, polype, u xơ dưới niêm mạc, vách ngăn, dính buồng, quá sản niêm mạc... gây ra rong kinh, rong huyết, ra máu bất thường đặc biệt gây vô sinh, sảy thai liên tiếp, thiếu máu do ra máu kéo dài. Các bất thường này ảnh hưởng rất nhiều đến kinh tế và cuộc sống của người bệnh. Việc phát hiện, chẩn đoán sớm các bệnh lý trên giúp thây thuốc lâm sàng ra quyết định kịp thời điều trị tích cực nhằm hạn chế tối đa các biến chứng, đảm bảo chất lượng cuộc sống cho bệnh nhân.

Ngày nay, đề chẩn đoán các bất thường trong buồng tử cung, ngoài biểu hiện của các triệu chứng lâm sàng, đã có một số phương pháp thăm dò hỗ trợ có tính chất quyết định như: siêu âm, chụp buồng tử cung có bơm thuốc cản quang [3], [4], [5]. 
Siêu âm tuy đơn giản, không độc hại nhưng độ nhạy và độ đặc hiệu không cao. Hiện nay, biện pháp siêu âm bơm nước vào buồng tử cung cho phép chẩn đoán u xơ tử cung, polype buông tử cung chính xác hơn.

Mô bệnh học là tiêu chuẩn vàng để chẩn đoán tổn thương trong các bệnh lý về buồng tử cung. Theo Christian D và CS (1992), tỉ lệ chẩn đoán mô bệnh học dương tính cao [9]

Hiện nay, tại Bệnh viện Đại học Y Thái Bình chưa có nghiên cứu đối chiếu về hình ảnh siêu âm với kết quả mô bệnh học nhằm mục đích hỗ trợ trong chẩn đoán và điều trị các bệnh lý buồng tử cung. Vì vậy, chúng tôi làm đề tài: Đối chiếu hình ảnh siêu âm buồng tử cung với kêt quả mô bệnh học của bệnh nhân đến khám tại Bệnh viện Đại học Y Thái Bình.

\section{II. ĐỐI TƯợNG VÀ PHƯƠNG PHÁP NGHIÊN CỨU \\ 2.1. Đối tượng}

\subsubsection{Tiêu chuẩn lựa chọn bệh nhân}

Đối tượng nghiên cứu là 73 bểnh nhân đến khám tại Khoa Sản - Phụ khoa, Bệnh viện Đại học Y Thái Bình trong năm 2018.

- Có siêu âm và kết quả mô bệnh học.

- Bệnh nhân đồng ý tham gia nghiên cứu

\subsubsection{Tiêu chuân loại trừ}

- Mắc bênh tim phổi

- Chảy máu nặng ở tử cung

- Bệnh ác tính ở cổ tử cung

- Viêm nhiễm đường sinh dục

- Tử cung to khi đo buồng tử cung kích thước $>10 \mathrm{~cm}$

2.2. Địa điểm và thời gian nghiên cứu

- Khoa Chẩn đoán hình ảnh và Khoa Sản Phụ khoa, Bệnh viện Đại học Y Thái Bình trong năm 2018.

2.3. Phương pháp nghiên cứu. Nghiên cứu được thực hiện theo phương pháp mô tả cắt ngang.

2.4. Kỹ thuật chọn mẫu. Chọn tất cả các bênh nhân có đủ tiểu chuẩn nghiên cứu từ 01/01/2018 đến khi đủ cõ̃ mẫu thì dừng lại.

\subsection{Nội dung nghiên cứu}

2.5.1. Nội dung, các biến số/chỉ số nghiên cứu

- Kết quả chụp siêu âm tử cung.

- Kết quả mô bệnh học.

2.5.2. Tiêu chuẩn chẩn đoán hình ảnh siêu âm tử cung

Dựa theo tiêu chuẩn của Bộ môn Chẩn đoán hình ảnh - Trường Đại học Y Hà Nội [1].

- U xơ tử cung

- Quá sản niêm mạc tử cung

- Polype niêm mạc tử cung

- Thiểu sản
- Ung thư biểu mô tử cung

2.6. Xử lú số liệu. Số liệu nghiên cứu được xử lý theo phương pháp thống kê y học bằng chương trình SPSS 16.0.

\section{KẾT QUẢ NGHIÊN CỨU}

3.1. Đặc điểm hình ảnh siêu âm và soi buồng tử cung

\section{Bảng 3.1. Kêt quả siêu âm}

\begin{tabular}{|c|c|c|}
\hline Siêu âm & $\begin{array}{c}\text { Số bệnh } \\
\text { nhân (n) }\end{array}$ & $\begin{array}{c}\text { Tỷ lệ } \\
\text { \% }\end{array}$ \\
\hline Polype niêm mạc tử cung & 43 & 14,4 \\
\hline $\begin{array}{c}\text { U xơ tử cung dưới niêm } \\
\text { mạc }\end{array}$ & 21 & 7,0 \\
\hline Tứ cung 2 buồng & 2 & 0,6 \\
\hline Niêm mạc tử cung mỏng & 1 & 0,3 \\
\hline Niêm mạc tử cung dày & 6 & 2,0 \\
\hline Bình thường & 227 & 75,7 \\
\hline Tống & $\mathbf{3 0 0}$ & $\mathbf{1 0 0}$ \\
\hline
\end{tabular}

Nhân xét: Có $24,3 \%$ trường hợp có hình ảnh siểu âm bất thường, trong đó, polype niêm mạc tử cung chiếm tỷ lệ cao nhất là 14,4\%.

Bảng 3.2. Kêt quả mô bệnh học

\begin{tabular}{|c|c|c|}
\hline Mô bệnh học & $\begin{array}{c}\text { Số bệnh } \\
\text { nhân }(\mathbf{n})\end{array}$ & $\begin{array}{c}\text { Tỷ lệ } \\
\text { \%o }\end{array}$ \\
\hline Bình thường & 15 & 20,5 \\
\hline Viêm niêm mạc tử cung & 3 & 4,1 \\
\hline Polype niêm mạc tử cung & 16 & 21,9 \\
\hline U xơ tứ cung & 9 & 12,3 \\
\hline Quá sản niêm mạc tữ cung & 24 & 32,9 \\
\hline Ung thư niêm mạc tứ cung & 1 & 1,4 \\
\hline Gai rau & 3 & 4,1 \\
\hline Vết tích bào thai & 1 & 1,4 \\
\hline Lạc niêm mạc tử cung & 1 & 1,4 \\
\hline Tống & $\mathbf{7 3}$ & $\mathbf{1 0 0}$ \\
\hline
\end{tabular}

Nhận xét: Có 79,5\% người bệnh có kết quả mô bệnh học bất thường. Trong đó: Quả sản niêm mạc tử cung chiếm tỷ lệ cao nhất là $32,9 \%$. Polype niêm mạc tử cung là $21,9 \%$.

3.4. Đối chiếu hình ảnh siêu âm với kết quả mô bệnh học

Bảng 3.3. Kêt quả chẩn đoán quá sản NMTC qua siêu âm đôî chiếu với mô bệnh hoc

\begin{tabular}{|c|c|c|c|}
\hline Siêu âm bệnh học & Có & Không & Tổng \\
\hline Có & 3 & 0 & 3 \\
\hline Không & 21 & 49 & 70 \\
\hline Tống & $\mathbf{2 4}$ & $\mathbf{4 9}$ & $\mathbf{7 3}$ \\
\hline
\end{tabular}

Nhận xét: Độ nhạy của siêu âm trong chẩn đoán quá sản NMTC là $13 \%$, độ đặc hiệu là 100\%, giá trị chẩn đoán dương tính,âm tính lần lượt là $100 \%$ và $70 \%$. 
Bảng 3.4. Kêt quả chẩn đoán polype buồng TC qua siêu âm đối chiếu với mô bênh hoc

\begin{tabular}{|c|c|c|c|}
\hline Miêu bâ bệnh học & Có & Không & Tổng \\
\hline Có & 13 & 17 & 30 \\
\hline Không & 3 & 40 & 43 \\
\hline Tống & $\mathbf{1 6}$ & $\mathbf{5 7}$ & $\mathbf{7 3}$ \\
\hline
\end{tabular}

Nhận xét: Độ nhạy của siêu âm trong chẩn đoán polype buồng TC là $81 \%$, độ đặc hiệu là $70 \%$, giá trị chẩn đoán dương tính, âm tính lần lượt là $43 \%$ và $93 \%$.

Bảng 3.5. Kêt quả chẩn đoán u xơ tử cung qua siêu âm đối chiếu với mô bệnh học

\begin{tabular}{|c|c|c|c|}
\hline Siêu ầ bệnh học & Có & Không & Tổng \\
\hline Có & 6 & 4 & 10 \\
\hline Không & 3 & 60 & 63 \\
\hline Tống & $\mathbf{9}$ & $\mathbf{6 3}$ & $\mathbf{7 3}$ \\
\hline
\end{tabular}

Nhận xét: Độ nhạy của siêu âm trong chấn đoán u xơ TC là $67 \%$, độ đặc hiệu là $94 \%$, giá trị chẩn đoán dương tính, âm tính lần lượt là $60 \%$ và $95 \%$.

\section{BÀN LUÂ̂N}

4.1. Đặc điểm hình ảnh siêu âm buông tử cung và mô bệnh học

\subsubsection{Kêt quả siêu âm buồng tử cung}

Kết quả bảng 3.1 của nghiên cứu này cho thây: có $24,3 \%$ trường hợp có siêu âm bất thường. Kết quả thấp hơn nhiều so với nghiên cứu của Đặng Thị Minh Nguyệt (2006). Theo tác giả, có $63,1 \%$ bệnh nhân có hình ảnh siêu âm bất thường. Có sự khác biêtt này theo chúng tôi là do đối tượng nghiên cứu khác nhau, nghiên cứu này chủ yếu là những người bệnh vô sinh còn nghiên cứu của tác giả trên chủ yếu là những người bệnh ra máu âm đạo bất thường $[6],[7],[8]$.

Trong các bất thường trên hình ảnh siêu âm, polype NMTC chiếm tỷ lệ cao nhất là $14,4 \%$, kết quả này cao hơn nghiên cứu của Đặng Thị Minh Nguyệt (2006) là $12 \%$. Siêu âm có thể nhìn thây polype buồng tử cung nhưng khó xác định được vị trí chân polype. Hiện nay, siêu âm bằng bớm nước vào buồng tử cung có thể phát hiện được những polype có kích thước nhỏ và còn có thể phát hiện được chính xác kích thước và vị trí của chân polype [6],[7],[8].

Một số hình ảnh siêu âm khác như: u xơ tử cung là $7,0 \%$; niêm mạc tử cung dày là $2,0 \%$. Một số hình ảnh khác: tử cung 2 buồng $(0,6 \%)$, niềm mạc tử cung mỏng $(0,3 \%)$.

Theo Đặng Thị Minh Nguyệt (2006), hình ảnh niêm mạc tử cung mỏng trên siêu âm chiếm $24,9 \%$ và niêm mạc tử cung dày chiếm $18,7 \%$. Kết quả cao hơn rất nhiêu so với nghiên cứu của tôi.

4.1.2. Kết quả mô bệnh học. Nghiên cứu này có $79,5 \%$ người bệnh có kết quả mô bệnh học bất thường. Trong đó, quá sản niêm mạc tử cung chiếm tỷ lệ cao nhất là $32,9 \%$. Các tỉ lệ bênh lý của buồng tử cung rất khác nhau theo từng lứa tuổi nên khác nhau theo từng nghiên cứu. Kết quả nghiên cứu này phù hợp với nghiên cứu của Bensimhon E (1980), tỉ lệ tổn thương buồng tử cung gặp nhiều nhất là quá sản niêm mạc tử cung, chiếm 29\%. Theo Christian D (1992) tổn thương gặp nhiều nhất là polype buồng tử cung [9]. Theo Đặng Thị Minh Nguyệt (2006), tổn thương gặp nhiều nhất là teo niêm mạc tử cung, chiếm $35,1 \%$.

Tỉ lệ bệnh nhân bị quá sản niêm mạc tử cung trên mô bệnh học của chúng tôi khá phù hợp với nghiên cứu của Đặng Thị Minh Nguyệt (2006) [7]. Kết quả của tôi cao hơn nghiên cứu của tác giả Christian D (1992) là 21,3\%[9].

Kết quả mô bệnh học là polype niêm mạc tử cung theo nghiên cứu này là $21,9 \%$, cao hơn nghiên cứu của Đặng Thị Minh Nguyệt (2006) [8]. Tuy nhiên, kết quả của chúng tôi lại thấp hơn với nghiên cứu của Christian D (1992) là $29,1 \%[9]$.

U xơ dưới NMTC theo nghiên cứu này cũng chiếm tỉ lệ cao là 12,3\% (Bảng 3.2). Tỉ lệ của tôi cao hơn nghiên cứu của Đặng Thị Minh Nguyệt (2006) là 4,6\% [8] và thấp hớn nghiên cứu của Christian D (1992) là 22,6\%[9].

Sở dĩ có sự khác biệt trên theo tôi là do khác biệt về địa điểm nghiển cứu, đối tượng nghiên cứu và phương pháp nghiên cứu giữa các tác giả là khác nhau.

Một số hình ảnh mô bệnh học khác trong nghiên cứu này như: viêm niêm mạc tử cung $(4,1 \%)$, gai rau $(4,1 \%)$, ung thư niểm mạc tử cung $(1,4 \%)$, vết tích bào thai $(1,4 \%)$, lạc niêm mạc tử cung $(1,4 \%)$.

4.2. Đối chiếu kết quả siêu âm với mô bệnh học

- Theo bảng 3.3 kết quả cho thấy độ nhạy của siêu âm trong việc chẩn đoán quá sản niêm mạc tử cung là $13 \%$; độ đặc hiệu là $100 \%$; giá trị chẩn đoán dương tính là $100 \%$ và giá trị chẩn đoán âm tính là $70 \%$. Như vậy, độ nhạy của siêu âm là không được cao trong việc chẩn đoán quá sản niêm mạc tử cung

- Kết quả bảng 3.4 cho thây độ nhạy của siêu âm trong chẩn đoán polype buồng tử cung là $81 \%$; độ đặc hiệu là $70 \%$; giá trị chẩn đoán 
dương tính là 43\% và giá trị chẩn đoán âm tính là 93\%. Như vậy, siêu âm cũng có giá trị khá cao trong chẩn đoán các trường hợp polype buồng tử cung trên lâm sàng.

- Thoe kết quả bảng 3.5 của nghiên cứu này cho thấy độ nhạy của siêu âm trong chẩn đoán u xơ tử cung là $67 \%$; độ đặc hiệu là $94 \%$; giá trị chẩn đoán dương tính là $60 \%$ và giá trị chẩn đoán âm tính là 95\%. Kết quả trên cho thấy: siêu âm có độ đặc hiệu và giá trị chẩn đoán âm tính cao trong chẩn đoán u xơ tử cung.

\section{KẾT LUÂ̂N}

- Chẩn đoán quá sản niêm mạc tử cung độ nhạy của siêu âm là 13\%; độ đặc hiệu là 100\%; giá trị chẩn đoán dương tính là $100 \%$ và giá trị chẩn đoán âm tính là 70\%

Chẩn đoán polype buông tử cung độ nhạy trên siêu âm là $81 \%$; độ đặc hiệu là $70 \%$; giá trị chẩn đoán dương tính là $43 \%$ và giá trị chẩn đoán âm tính là 93\%

- Chẩn đoán u xơ tử cung độ nhạy của siêu âm là 67\%; độ đặc hiệu là 94\%; giá trị chẩn đoán dương tính là $60 \%$ và giá trị chẩn đoán âm tính là 95\%.

\section{TÀI LIỆ THAM KHẢO}

1. Bộ môn Chẩn đoán hình ảnh trường Đại học Y Hà Nô̂i (2001), Chẩn đoán X quang và hình ảnh y học, Nhà xuất bản $Y$ học, tr 15- 30.

2. Bộ môn Giải phâuu học (2006), Trường đại học Y'dước thành phố Hî́ Chí Minh, "Hế sinh dự nữ", Giải phâuu học tập 2, Nhà xuất bản $Y$ học, tr 301- 330.

3. Phan Trường Duyêtt (1999), "Siêu âm chẩn đoán về phụ khoa", Kỹ thuật siêu âm và ứng dụng trong sản phụ khoa, Nhà xuất bản khoa học và kỹ thuật Hà Nội, tr 5- 20.

4. Phan Trường Duyệt (2005), "Siêu âm chẩn đoán những thay đổi ở tử cung, nội mạc tử cung", Kỹ thuật siêu âm và ứng dụng trong sản phụ khoa, Nhà xuất bản Y hoc, tr. 372- 392.

5. Phan Trường Duyệt (2006), Kỹ thuật hiện đại ứng dụng trong thăm dò sản phụ khoa, Nhà xuất bản khoa hoc và kỹ thuât Hà Nôi.

6. Đăng Thị Minh Nguyệt (2006), "Giá trị soi BTC trong chẩn đoán dính và vách ngăn $\mathrm{BTC}^{\prime \prime}$, Tap chí y học Việt Nam, Số đặc biệt 2/2006, tr. 358-326.

7. Đăng Thi Minh Nguyêt (2006) "Đánh giá giá tri phương pháp soi BTC trong chẩn đoán quá sản niêm mạc tứ cung", Tạp chí y học Việt Nam, Số đăc biêt 2/2006, tr. 352-357.

8. Đặng Thị Minh Nguyệt (2006), "Soi BTC để chẩn đoán các bất thường trong buồng BTC", Luận án tiến sỹ y học, Trường Đại học Y Hà Nội.

9. Christian D et al (1992), "Hysteroscopic findings in postmenopausal bleeding", Hysteroscopy principles and practice, jB Lippincotte, Philadelphia. p. 132-134.

\title{
KIẾN THỨC VÀ THÁI Độ CỦA NHÂN VIÊN Y TẾ ĐỐI VỚI SA SÚT TRÍ TUÊ TẠI BỆNH VIỆN LÃO KHOA TRUNG ƯƠ'NG NĂM 2019
}

\author{
Nguyễn Trung Anh"1,2, Nguyễn Thị Hoài Thu1, \\ Trịnh Huyền $\mathrm{Chi}^{2}$, Đặng Thị Xuân ${ }^{3}$, Phạm Thắng ${ }^{1}$
}

\section{TÓM TĂT}

Sa sút trí tuê là môt bênh rất phổ biến ở người cao tuổi. Khoảng 6-10\% người trên 60 tuổi mắc bệnh sa sút trí tuệ. Tuy nhiên kiến thức và thái độ của nhân viên y tế với Sa sút trí tuệ còn hạn chế.Chúng tôi tiến hành nghiên cứu với muc tiêu đánh giá kiến thức và thái độ của nhân viên y tế đối với bệnh sa sút trí tuệ (SSTT) tại bênh viện Lão khoa Trung ương năm 2019. Đây là nghiên cứu cắt ngang được tiến hành từ tháng 04 đến tháng 12 năm 2019 tai bệnh viên Lão khoa Trung ương. Bác sĩ và điều dưỡng làm việc toàn thời gian tại bệnh viện Lão khoa Trung ương và đồng ý

${ }^{1}$ Bênh viện Lão khoa Trung ương

2Trường Đại học Y Hà Nội

${ }^{3}$ Trung tâm Chông Độc, bệnh viện Bạch Mai

Chịu trách nhiệm chính: Nguyễn Trung Anh

Email: trunganhvlk@gmail.com

Ngày nhận bài: 28.12.2020

Ngày phản biện khoa họ: 15.2.2021

Ngày duyệt bài: 26.2.2021 tham gia nghiên cứu. Chúng tôi sử dụng 02 bộ câu hỏi để phỏng vấn kiến thức và thái độ của nhân viên y tế bao gồm Alzheimer's Disease Knowledge Scale (ADKS) và the Dementia Attitudes Scale (DAS). Các biên khác sử dụng bao gồm tuổi, giới, nơi sống, trình độ học vấn, kinh nghiệm làm việc với bệnh nhân SSTT và tham dự bất kỳ khóa học nào về SSTT. Tổng số 142 nhân viên y tế tham gia có 130 điều dưỡng (91.5\%) và 12 bác sĩ (9.5\%). Tuổi dao động từ 20-39 tuổi.Tỉ lệ kiến thức tốt và rất tốt là $97.2 \%$ còn tỉ lê thái đô rất tốt là $29.9 \%$.Kết quả cho thấy cải thiện thái độ của nhân viên y tế với SSTT rất quan trong và cần có nhiều chương trình đào tạo cũng như nghiên cứu để cải thiện kiến thức và thái độ của nhân viên đối với SSTT.

Tư khóa: sa sút trí tuệ, kiến thức và thái độ, nhân viên y tế,

\section{SUMMARY}

KNOWLEDGE AND ATTITUDES OF HEALTHCARE PROFESSIONALS TOWARDS DEMENTIA AT NATIONAL GERIATRIC HOSPITAL IN 2019 